\title{
A Estrutura Primitiva da Representação Social do Medo
}

\author{
Antonio Roazzi ${ }^{1}$ \\ Universidade Federal de Pernambuco \\ Fabiana C. B. Federicci \\ Universidade Federal de Pernambuco \\ Margaret Wilson \\ University of Camterbury, Inglaterra
}

\section{Resumo}

O estudo aborda a questão metodológica que caracteriza a pesquisa na área das representações sociais. Em particular, aprofundase no problema da verificação empírica do consenso que uma representação possui por um determinado grupo social. Esta preocupação metodológica foi abordada em um estudo cujo objetivo era reconstruir a trama primitiva da representação social do medo em crianças de sete a dez anos de idade com experiências sócio-culturais diferentes (escola particular e orfanato). O interesse principal era analisar o papel da experiência na construção deste tipo de representação. Primeiramente, com um grupo de 30 crianças, foi coletada a informação da representação, entendida como meio de acesso ao campo das representações, através do método da associação livre (pedia-se para que as crianças expressassem de maneira livre o que pensavam com a evocação da palavra medo). A partir deste levantamento foram selecionadas 15 palavras entre as mais evocadas pelos dois grupos de crianças e em seguida, foi investigado o nível de consenso da representação social do medo através da técnica não-verbal de classificação. A um segundo grupo de 58 crianças, foi solicitado a pensar sobre as 15 palavras que estavam representadas em cartões e a ordená-las em grupos em função de estarem mais ou menos associadas com a sensação de medo. Os dados analisados através de métodos estatísticos multidimensionais apontaram para a existência de similaridades e diferenças no que se refere ao nível de consenso dos diferentes grupos de crianças comparados em relação à representação social do medo. Além do mais, foi possível reconstruir o significado e a atitude geral das crianças em relação ao medo. Estes resultados são discutidos focalizando, em particular, os problemas metodológicos no estudo das representações sociais, especificamente no que se refere ao estabelecimento objetivo do nível de consenso no estudo destas.

Palavras-chave: Medo; representação social; emoção; cultura; técnica não-verbal de classificação.

Primitive Structure of the Social Representation of Fear

\begin{abstract}
This study examined a methodological approach to research on social representations. The approach provides an empirical validation of the possibility that a representation has a consensus among a certain social group. This methodological approach is illustrated in a study that aimed at revealing the structure of the social representation of fear among children from seven to ten-years old, with different social and cultural backgrounds (private schools and orphanages). The main aim was to examine the role of social background in establishing this kind of representation. First, with a group of thirty children, the elements of the representation were collected through a free association method, which consisted of asking the children to express what they thought of when the word 'fear' was evoked. From this information, fifteen kinds of fears were selected from those that had been evoked most frequently by the two groups of children. The social representation of fear was examined using a nonverbal sorting technique with a second group of fifty-eight children. They were asked to think of about fifteen words that were presented on cards and to place them in order according to their higher or lower level of association with the sensation of fear. The data were analysed using non-metric multidimensional scaling techniques (SSA, MSA) and pointed to the existence of similarities and differences in consensus levels between the different child groups compared with respect to the representation of fear in society. In this way it was possible to establish the meaning and the general attitude of the children in relation to fear. The results are discussed emphasising the methodological problems associated with the study of social representations, referring to the objective establishment of consensus level.

Keywords: Fear; emotion; social representation; culture; non-verbal sorting technique.
\end{abstract}

\footnotetext{
${ }^{1}$ Endereço para correspondência: Universidade Federal de Pernambuco, $\mathrm{CFCH}, 8^{\circ}$ andar, Cidade Universitária, Rua Acadêmico Hélio Ramos, s/n, 50670-901, Recife, PE. Fone: (81) 32710599, Fax: (81) 32711843. E-mail: roazzi@npd.ufpe.br
} 
A pesquisa sobre as representações sociais encontrase em um momento de indagação. Ela busca uma reflexão sobre si mesma, sobre questões metodológicas e principalmente sobre como produzir conhecimentos que representem a globalidade do problema. As representações sociais, por serem um elo de ligação entre o real, o psicológico e o social, são capazes de estabelecer conexões entre a vida abstrata do saber, das crenças e a vida concreta do indivíduo em seus processos de troca com os outros. Sendo assim, o estudo das representações sociais significa tentar compreender não somente o que as pessoas pensam de um objeto, cujo conteúdo possua um valor socialmente evidente e relevante, mas também como e porque o pensam daquela forma. Nesta perspectiva, emerge, de forma nítida, o papel do significado dos processos de simbolização e da atividade cognitiva em relação ao sentido que o mundo externo assume ao nível da vida psíquica.

Este nosso artigo procura ir de encontro a estas preocupações e, a partir de um questionamento das metodologias utilizadas na área das representações sociais, visa verificar a hipótese do consenso das representações (Roazzi, 1999a). Qual o nível de consenso acerca dos significados relativos à natureza social da representação social? Qual o nível de consenso ou o compartilhar do qual uma determinada representação é objeto, em um determinado grupo ou grupos, que possibilite assim, comparações entre as representações que grupos diferentes fazem de um mesmo objeto (e.g., Galli \& Nigro, 1986; Le Bouedec, 1979; Monteiro \& Roazzi, 1987; Nigro \& Galli, 1988; Roazzi, 1999a; Roazzi, 1999b; Roazzi \& Monteiro, 1991, 1995; Roazzi, Federicci \& Carvalho, 1999)? É preciso lembrar também que as representações sociais, como as teorias científicas, as religiões e as mitologias, são sempre as representações de algo e de alguém (Moscovici, 1984). Nesta perspectiva, o presente estudo preocupou-se em examinar se crianças com experiências diversas têm compreensões diferentes da emoção do medo.

\section{Emoções e Estudos sobre o Medo}

O estudo das emoções é um processo e um construto muito importante e complexo da psicologia para compreendermos as dinâmicas do comportamento humano em sua plenitude. ${ }^{2}$ Esta complexidade deriva

\footnotetext{
2 Em suas teorizações iniciais, a emoção tem sido vista por perspectivas bastante diferentes. Entre as principais perspectivas, podem ser citadas as que vêem a emoção como (1) consciência de mudanças corporais (James, 1966/1890); (2) atividade talâmica (Cannon, 1932); (3) sistema de sinalização (Mowrer, 1960); e (4) interpretação de eventos (Schachter, 1967).
}

especialmente do fato de que as emoções e suas formas de expressão mudam no decorrer da vida do indivíduo, o que é a causa de uma série de mudanças como, por exemplo, mudanças (1) na situação capaz de gerar a emoção; (2) no comportamento instrumental motivado pelas emoções; (3) nos tipos de expressões indicando a emoção; (4) nos mesmos estados emocionais que se tornam mais sofisticados no decorrer do desenvolvimento; e (5) nas mudanças das convenções sociais, socialização das expressões emocionais (Buck, 1984; Campos, 1983; Ekman, 1972, 1982; Ekman \& Oster, 1979; Feldman, 1982; Gnepp \& Hess, 1986; Izard, 1979; Plutchick, 1980; Sherer \& Ekman, 1984; Sroufe, 1979).

Nas últimas décadas, o estudo das emoções, depois de um período de esquecimento, vem sendo redescoberto sob uma nova dimensão. Este ressurgimento tem sido influenciado por uma série de desenvolvimentos de pesquisa, especialmente nas áreas do funcionamento cerebral - lateralização hemisférica (Ellis, 1983; Heilman \& Satz, 1983; Gazzaniga \& Le Doux, 1978; Gordon, 1983; Hassler, 1990; Ross, 1981), do comportamento animal - estudos etológicos - (Goodall, 1971, 1979; Harlow, 1971; Mason, 1961; Miller, Banks \& Kuwahara, 1966; Miller, Banks \& Ogawa, 1962; 1963) e das expressões das emoções humanas - especialmente a comunicação não verbal (Buck, 1975, 1977, 1978; Buck, Savin, Miller \& Caul, 1969). Mas, apesar da riqueza das contribuições produzidas neste âmbito, seu conhecimento ainda encontra-se bem longe de estar exaurido até na definição de seus conceitos básicos. ${ }^{3}$ A efervescência na área encontra-se somente em seu estágio inicial. Além do foco de análise e da definição das diferentes perspectivas teóricas do processo evolutivo que conduz as crianças a uma compreensão de emoções sociais, permanecem também divergências tanto sobre a maneira de pensar as

\footnotetext{
3 No momento da atual pesquisa sobre as emoções existe um desacordo substancial até sobre sua própria definição. A questão levantada há mais de 100 anos atrás por William James "What is emotion?" ainda permanece em aberto e, dificilmente, propostas para uma definição estão isentas de questionamentos e debates (Amerio \& Di Lauro, 1985). Paul Fraisse, na introdução do capítulo sobre a natureza das emoções em seu livro "Tratado de psicologia experimental", editado conjuntamente com Jean Piaget (1981), afirma: "Do que se fala? Em todos os discursos é essencial definir com precisão os conceitos utilizados. No caso da emoção, a tarefa é difícil e, portanto não existe um consenso entre os vários autores; um, inclusive, em obra recente (Strongman, 1973), renuncia até de maneira explícita, em propor sua própria definição para não aumentar a confusão. Seria tudo muito mais simples se a emoção correspondesse a uma única categoria de fatos ou se dependesse de uma só variável independente ou intermediária fácil de ser identificada" (Fraisse \& Piaget, 1975, p.129).
} 
emoções, como na maneira de entender o comportamento humano.

Nesse quadro geral de elaboração de novas perspectivas teóricas, quando se enfrenta a questão relativa à classificação das teorias psicológicas sobre as emoções, é possível reconhecer duas grandes categorias que se definem a partir da ausência ou da presença do fator cognitivo, ou melhor, da independência/dependência das emoções do cognitivo. Nos últimos anos, o papel desempenhado por este fator no estudo das emoções tem se tornado amplamente investigado e discutido na literatura: quais as bases cognitivas dos inúmeros aspectos da dimensão emocional?

Esta preocupação em estabelecer conexões entre cognitivo e emocional é expressa por Mandler (1982) nesta citação: "As emoções da criança, assim como as do adulto, são construídas a partir de uma variedade de eventos, incluindo aqueles de natureza cognitiva e visceral, de estruturas inatas e aprendidas e de sinais culturais e idiossincráticos. Como a abordagem construtivista tem vivificado os estudos contemporâneos sobre a linguagem, a memória e a percepção, então esta abordagem aplicada para o estudo das emoções poderia permitir novas descobertas em relação ao desenvolvimento da criança." (p.343)

As evidências empíricas e as teorias cognitivas sobre as emoções, de acordo com as quais as atividades cognitivas participam de maneira substancial na gênese e estruturações das emoções (ver Amerio, 1986a; 1986b; 1987; Amerio \& Di Lauro, 1985; Ausebel \& Sullivan, 1983; Garcia, 1992; Lewis, 1992; Michalson \& Lewis, 1985; Orthony, Clore \& Collins, 1988; Reissland, 1985; 1988; Russell, 1989; Schwartz \& Trabasso, 1984; Stein \& Levine, 1989; Trentin, 1988; Wimmer \& Perner, 1983) constituem um importante ponto de partida para tentar iniciar um discurso sobre estas em uma perspectiva sóciopsicológica (e.g., Gnepp, 1983; Lewis \& Saarni, 1985; Saarni, 1989). Uma abordagem do tipo psicossocial pressupõe uma passagem da cognição para a cognição social; isto é, pressupõe que, para compreender o comportamento humano, devem ser consideradas não somente as estruturas e organizações cognitivas e suas formas de interação e combinação, mas também o conteúdo e as origens sociais das mesmas. Afinal, as emoções de um indivíduo não são governadas unicamente pelo êxito de suas ações, mas também pela antecipação da aprovação ou desaprovação que os outros manifestam em relação a ações que atendem ou não a determinadas regras ou normas (Harris, 1989).

Diante deste contexto teórico sobre o estudo evolutivo das emoções, surge a idéia de planejar um estudo cuja finalidade é investigar a emoção do medo sob uma perspectiva psicossocial, tendo como base a teoria das representações sociais. ${ }^{4}$ Este interesse surgiu do fato de que, apesar do medo ter sido objeto de muitas análises e investigações (e.g., Kagan, 1975; Lewis \& Rosenblun, 1975; Oliverio Ferraris, 1977; 1980; Zlotowicz, 1974), ainda são quase inexistentes pesquisas que focalizam o estudo da trama primitiva do medo em uma perspectiva sóciocognitiva. Uma única investigação tem tratado de estudar, de maneira exploratória, este tipo de emoção nesta perspectiva, a de Nigro e Galli (1988). Estes autores estavam interessados, em primeiro lugar, no estabelecimento da caracterização da emoção medo em crianças e, em seguida, detectar diferenças nesta caracterização em função da experiência de vida das mesmas. Neste sentido, consideraram duas amostras de crianças entre dez e 14 anos de idade, que moravam em contextos sociais diferentes (crianças que viviam no contexto urbano e crianças que viviam no contexto rural da Itália). Tal investigação foi realizada através do uso de três tipos de técnicas básicas - a associação livre, o diferencial semântico e as avaliações emparelhadas.

Os resultados, tratados através da análise das correspondências binárias, não indicaram diferenças significativas entre os dois grupos de crianças: o tipo de representação social do medo foi muito parecido entre as crianças que viviam em contexto urbano e as crianças que viviam em contexto rural. Considerando os tipos de medo que têm emergido, estes confirmam o que já é conhecido na literatura na área, no contexto de crianças italianas (Oliverio Ferraris, 1980; Oliverio Ferraris \& Pilleri Senatore, 1986). O dado mais interessante foi a relação encontrada entre os vários tipos de medo, isto é, a distância-proximidade emotivo-cognitiva entre os vários tipos. Por exemplo, 'medo do exame' foi associado com medo do tipo simbólico, como o 'medo do escuro' e o 'ficar só'. Por sua vez, o 'medo do sangue' distingue-se de maneira nítida do 'medo da morte', seguramente pelo fato do sangue estar associado ao sentido da vida. Pelo contrário, o 'medo da morte' está estritamente associado

\footnotetext{
4 O estudo do medo, de acordo com a teoria das representações sociais, definida como o sistema de valores, idéias e práticas, permite, não somente que se estabeleça uma ordem para tornar os indivíduos capazes de orientarse em seu próprio mundo material e social e de dominá-lo, mas também que se torne possível a comunicação entre as pessoas. Neste contexto é importante estudar como, em suas áreas específicas, a representação social estrutura-se como código para a troca social entre os indivíduos. No caso específico da emoção do medo, a questão pode ser colocada da seguinte forma: Quais os primórdios da representação social do medo? Qual sua gênese? Qual sua trama primitiva? Como as pessoas estruturam-na em suas trocas sociais?
} 
ao 'medo da droga' em uma relação de causa/efeito. Enfim, outro dado muito interessante foi a constatação de que o 'medo do filme de terror' é capaz de evocar uma série de outros medos, provavelmente pelo fato de representar uma síntese de diferentes medos.

Este estudo apresenta-se muito interessante, especialmente pelo seu caráter heurístico e pela nova perspectiva que aponta para o estudo do conteúdo emocional do medo. De toda maneira, apresenta também limitações devido aos tipos de técnicas utilizadas com crianças, as quais são apontadas pelos próprios autores. Contudo, também estão sendo realizados estudos de tipo qualitativo na mesma área, para que se tenha acesso a informações mais ricas.

Esta investigação insere-se nas mesmas preocupações apontadas por Nigro e Galli (1988), e tento o papel de reconstruir a trama primitiva da representação social do medo, planejou-se uma investigação cujo objetivo era, em primeiro lugar, ampliar o campo de conhecimento deste tipo de representação em crianças, utilizando procedimentos mais apropriados para esta faixa etária, enfatizando técnicas não verbais na avaliação de dados. E, em segundo lugar, além de reconstruir em um outro contexto nacional, o Brasil, investigar objetivamente a representação social do medo a partir de uma comparação entre grupos de crianças que apresentam experiências sócio-culturais muito mais acentuadas do que as investigadas no estudo de Nigro e Galli, isto é, crianças de nível sócio-econômicos e experiências familiares diferentes.

\section{Estudo}

A investigação dividiu-se em duas fases. Na primeira, foi levantado o componente "informação da representação" (entendido como meio de acesso ao campo das representações) através do método ou técnica da associação livre em uma amostra de crianças de escola particular e de orfanato. Solicitava-se às crianças que expressassem de maneira livre, o que se passava em suas mentes quando evocada a palavra-estímulo medo. A partir do levantamento, foram selecionados quinze itens que eram mais freqüentemente associados pelas crianças. Em seguida, na segunda fase, a partir deste levantamento, foi investigado, em uma amostra similar a da primeira fase, o campo semântico da representação social do medo através do Procedimento de Classificações Múltiplas (Multiple Sorting Procedure), visando, especialmente, reconstruir a trama e os tipos de modalidades de estruturação deste campo (ver Roazzi, 1995).

Em um primeiro momento, através da Análise Escalonar Multidimensional (MSA - Multidimensional
Scalogram Analysis) das classificações livres realizadas por crianças de escola particular, explorou-se o tipo de regionalização dos quinze itens e a relação destas regiões com o item medo. Em um segundo momento, através da Análise dos Menores Espaços (SSA - Smallest Space Analysis ou Similarity Structure Analysis) de uma classificação dirigida (associação dos quinze itens com medo), objetivou-se entender, com mais detalhes, a estrutura das relações entre estas regiões, tanto em crianças de escola particular como em crianças de orfanato.

\section{Questão Metodológica}

O objeto de estudo desta pesquisa e seu método de investigação, revela principalmente uma preocupação, de cunho metodológico, que precisa de alguns esclarecimentos introdutórios sobre as razões que nortearam esta nossa preocupação, e que nos levaram ao planejamento do estudo desta forma antes de entrar no mérito do estudo em si. De fato, a escolha da metodologia de pesquisa utilizada neste estudo foi, em grande parte, influenciada não somente pelas críticas teóricas a sua forma de coletar e analisar os dados, mas principalmente pelas técnicas analíticas disponíveis para lidar com eles. Dois fatores principais levaram a escolha dos métodos de análise: 1) a natureza essencialmente qualitativa dos dados, que requereria o uso de um tipo de estatística não-paramétrica; e, 2) a natureza do assunto estudado, que necessitava de procedimentos estatísticos que mantivessem a integridade dos dados. Neste sentido, toda a gama de análises multidimensionais não-métricas tem demonstrado ser bem adequada para atender a estas duas exigências (Shepard, 1962; Schiffman, Reynolds \& Young, 1981; Shye, 1978; Shepard, 1962; Souza, 1988; Torgerson, 1952, 1958).

Dado que estes tipos de análises estão baseados em processos de categorização, adotando principalmente técnicas não verbais, que encontram suas raízes nas origens da própria psicologia, especialmente da cognitiva e da social, estes esclarecimentos vertem sobre a emergência de sistemas conceituais e sua relação com o processo de categorização.

\section{Sistemas Conceituais e Categorias}

Em psicologia não é novidade que, a forma como os indivíduos conceitualizam o mundo a sua volta está diretamente relacionada com a habilidade de formar categorias e de construir sistemas de classificação, pelas quais estímulos diferentes entre si possam ser tratados como equivalentes em categoria (Kelly, 1955). De fato, o significado que o indivíduo possui no mundo que está a sua volta é construído sobre uma rede de categorizações. 
Tajfel (1981) afirma: “O papel da categorização em percepção e em outras atividades cognitivas tem desempenhado, durante muitos anos, um papel fundamental na formulação de teorias em psicologia" (p. 305). Esta compreensão, da forma como as pessoas categorizam e atribuem conceitos a estas categorizações, é uma questão central para que se possa compreender o comportamento humano. Qual a natureza dos conceitos que as pessoas formulam e como estes são organizados em sua relação com o mundo com o qual está continuamente em interação?

Um dos procedimentos para explorar a forma como as pessoas categorizam e elaboram sistemas de classificação, é o Procedimento de Classificações Múltiplas. Esta metodologia de investigação se desenvolve a partir dos procedimentos de categorias-próprias de Sherif e Sherif (1969) e das tarefas de classificação usadas por Vygotsky (1934). Este procedimento vem se consolidando como metodologia apropriada para pesquisa de sistemas conceituais em várias áreas da psicologia, como, por exemplo, a Psicologia Social (Eckman, 1975; Tajfel, 1981) e a Psicologia Ambiental (Canter \& Comber, 1985; Groat, 1982; Ward \& Russell, 1981; Wilson \& Canter, 1990).

O Procedimento de Classificações Múltiplas está em contraste com a maioria das investigações psicológicas do passado que utilizam técnicas analíticas que assumem uma dimensionalidade e, portanto, não permitem descobrir formas categóricas não pressupostas de construção do mundo. O Procedimento de Classificações Múltiplas sublinha o aspecto qualitativo, não somente das categorias, mas também da construção do sistema de classificação que os indivíduos utilizam para se relacionarem no mundo complexo no qual vivem.

Este sistema é, assim, por excelência, um método que permite a exploração de sistemas conceituais tanto no aspecto individual, como de grupo. De fato, classificar, categorizar, convencionalizar, são faces de um mesmo processo que permite a todos saber o que denota o que, e estão presentes em todas as nossas atitudes, ações e comunicações.

É importante fazer uma distinção entre processos de categorização e explicações ordinárias que as pessoas dão as suas ações. De fato, a compreensão do sistema de categorização utilizado pelas pessoas e a forma com que designam conceitos a estas categorias, constituem a chave central para o entendimento do comportamento humano.

É importante também notar que, o sistema de classificações pressupõe uma compreensão intelectual e emocional dos fatos e que, o último elemento tem sempre um papel preponderante no processo. Deste modo, a forma como as pessoas classificam eventos não se constitui em fenômeno, ou estático ou uniforme, por sua própria natureza; ao contrário, este varia consideravelmente em forma e intensidade, dependendo do tempo, do local, da situação e do contexto.

Este sistema não é novo (Bruner, Goodnow \& Austin, 1956; Miller, 1956). Por exemplo, Bruner, Goodnow e Austin (1956) já apresentaram as possibilidades de explorar a natureza dos conceitos das pessoas estudando como estas designavam categorias a vários elementos, além de inúmeras pesquisas, principalmente voltadas ao estudo do processo de atribuição de significados, como as de Szalay e Deese (1978), estas explorações implicam um trabalho que envolve dados caracterizados, mais por sua profundidade do que por quantidade. Em seus pressupostos, existe uma tendência a trabalhar diretamente com as pessoas em seus próprios termos, a partir do respeito às habilidades destas para formular formas de pensamento sobre o mundo, assim como sobre suas experiências.

No caso de classificações livres, este sistema de classificação de elementos requer pouco do entrevistado: basicamente que este indique, segundo sua opinião, categorias a certos elementos, de acordo com características que estes possuam. Poucas são as limitações, e nenhuma exigência é feita quanto à maneira de processar a classificação. No caso de classificações dirigidas, sugerese, então, o critério da classificação, enquanto que o número de elementos em cada grupo, o número de grupos etc., são decisões do sujeito e não do experimentador. Assim uma das principais vantagens deste procedimento é a possibilidade de não oferecer limites ao sujeito na sua tarefa de formar categorias dos elementos apresentados; o sujeito apenas deve separar diversos elementos através do uso de diferentes critérios, formulados por ele mesmo, ou sugeridos pelo experimentador. Nesse procedimento, da mesma forma das entrevistas, o entrevistador procura identificar as suas categorias conceituais, assim como as suas classificações dos elementos. Neste caso, quanto maior for a liberdade dada ao entrevistado, mais provavelmente o entrevistador irá apreender algo sobre aquele e seu sistema de conceituação.

$\mathrm{O}$ ato de classificar é, sem dúvida, uma atividade comum no dia a dia. $\mathrm{O}$ ato de decidir roupa, escola das crianças, candidatos políticos, produtos domésticos no supermercado, requer uma seleção que se baseia em um esquema de categorização desenvolvida pelo indivíduo. O sistema de classificações múltiplas objetiva exatamente a compreensão destes esquemas pessoais. 
Em face da relevância deste processo de classificação, esta investigação estará baseada nestes princípios, tendo como objetivo estudar a forma como a emoção do medo se estrutura em crianças. Portanto, um procedimento de investigação que permita estudar os sistemas conceituais é fundamental. Através de estudos destes sistemas conceituais, dos conjuntos de regras que as pessoas utilizam para classificar situações, personagens e eventos, torna-se possível desvendar o significado de como o medo se estrutura em crianças.

\section{Participantes}

\section{Método}

Fase 1

Estudo de associação livre: nesta primeira fase participou um total de 40 crianças entre sete e dez anos de idade, igualmente distribuídas por cada faixa etária por ambos os sexos. Destas, 20 freqüentavam uma escola particular e 20 estudavam em um orfanato dirigido pelo governo estadual. A idade média dos dois grupos foi 8,3 e 8,5 , respectivamente.

Fase 2

Estudo de classificação livre e dirigida: a amostra de crianças entrevistadas nesta segunda fase foi de 58 crianças entre sete e dez anos de idade, também distribuídas por faixa etária, por ambos os sexos. Destas, 30 freqüentavam uma escola particular e 28 estudavam em um orfanato (o mesmo orfanato citado acima). A idade média dos dois grupos foi 9,4 e 8,9, respectivamente.

\section{Material}

O material para a investigação consistia em 15 cartões de $3 \times 4 \mathrm{~cm}$., cada um contendo a inscrição de um item daqueles selecionados por estarem freqüentemente mais associados com a palavra-estímulo medo. Estas palavrasestímulo estão apresentadas na primeira parte dos resultados. No caso da classificação livre era também apresentado um cartão com a palavra medo.

\section{Procedimentos \\ Associação livre}

As crianças eram entrevistadas individualmente. Para obter informações, assim como para conhecer o tipo de orientação positiva ou negativa das crianças em relação ao medo, pedia-se para que elas expressassem de maneira livre, o que passava em suas mentes quando evocada a palavra-estímulo medo. A partir do levantamento, foram selecionados quinze itens que eram mais freqüentemente indicados pelas crianças. Os itens e porcentagem de associação (em parênteses) estão apresentados na Tabela 1.

Estes quinze itens foram, em seguida, utilizados em uma tarefa de classificação para reconstruir o campo semântico e a estrutura da emoção medo.

\section{Classificação livre}

A tarefa de classificação múltipla consistiu em solicitar ao sujeito que apresentasse suas idéias e concepções sobre um assunto, utilizando vários elementos que foram agrupados ou separados, de acordo com sua similaridade, em função de diversos critérios estabelecidos. A multiplicidade das classificações, onde o sujeito classifica os mesmos elementos considerando aspectos diferentes, permite uma compreensão multifacetada do mesmo objeto ou evento (Guttman, 1968; Kruskal, 1964a, 1964b).

Em uma primeira fase, os itens eram classificados livremente, ou seja, o experimentador deixava a criança livre para classificar os vários itens de acordo com o critério que decidisse. Em seguida, o experimentador estabelecia o critério da classificação. Se, no começo, o sujeito demonstrasse alguma dúvida sobre o procedimento, o experimentador então apresentava exemplos a partir de outros tipos de estímulos. Por exemplo, apresentava ao sujeito três animais de brinquedos e perguntava que aspecto dois animais de brinquedos poderiam ter em comum que os tornassem diferentes de um terceiro animal.

"Considere, por exemplo, que nós tenhamos estes três animais de brinquedo, um urubu, um cavalo e um leão. Se você tiver que fazer um grupo com dois deles, aqueles que se assemelham por alguma

Tabela 1. Itens e Percentagens dos Itens Produzidos a Partir da Associação Livre

\begin{tabular}{lll}
\hline Itens e Percentagens & Itens e Percentagens & Itens e Percentagens \\
\hline 01 Rato $(4 \%)$ & 06 Monstro $(7,43 \%)$ & 11 Papafigo $(6,1 \%)$ \\
02 Morcego $(2,7 \%)$ & 07 Vampiro $(5,40 \%)$ & 12 Prova $(4 \%)$ \\
03 Barata $(4,7 \%)$ & 08 Fantasma $(11,49 \%)$ & 13 Doença $(5,4 \%)$ \\
04 Sanguessuga $(2,02 \%)$ & 09 Bruxa $(8,1 \%)$ & 14 Revólver $(8,1 \%)$ \\
05 Assaltante $(10,81 \%)$ & 10 Diabo $(10,13 \%)$ & 15 Morte $(9,5 \%)$ \\
\hline
\end{tabular}

\footnotetext{
${ }^{5}$ Estas instruções como as outras apresentadas a seguir, podiam ser alteradas pelo entrevistador em função das respostas da criança e seus questionamentos. O objetivo do entrevistador era que a criança compreendesse claramente as instruções e tarefas a serem executadas.
} 
característica em comum, quais você colocaria junto e qual seria o diferente dos outros dois?'

Então, por exemplo, se o sujeito colocasse o cavalo e o leão juntos, distinguindo-os do urubu, ou distinguindo o cavalo do urubu e do leão, pedia-se a ele para explicar a razão do agrupamento (ambos não voam, ou ambos são carnívoros, ou ambos têm pele e assim por diante). O objetivo era evidenciar o critério usado pelo sujeito.

$\mathrm{Na}$ classificação livre, que sempre antecedia as dirigidas, explicava-se ao sujeito o que era solicitado, isto é, a classificação das palavras-estímulo ou cartões em grupos de modo a termos, em cada grupo, elementos semelhantes ou que se conjuguem para um determinado fim. A criança era deixada livre para formar os grupos e alocar quantas palavras-estímulo ela quisesse em cada grupo, como também podiam formar quantos grupos quisessem. Após o agrupamento, o investigador tomava nota do conteúdo do grupo e os números de palavrasestímulo alocados em cada um. As instruções para a classificação livre eram as seguintes:

"Eu estou desenvolvendo um estudo sobre o que as pessoas pensam sobre determinadas palavras e o que estas palavras fazem pensar $e$ sentir. Então, eu estou pedindo a várias pessoas escolbidas ao acaso que analisem as seguintes palavras e que as ordene em grupos, de tal forma que todas as palavras em cada grupo sejam parecidas umas com as outras em um determinado aspecto e diferentes das palavras dos outros grupos. Vocêpode separar as palavras em quantos grupos quiser e colocar quantas palavras quiser em cada grupo. O que importa é sua opinião.

Depois eu vou pedir para você me dizer quais as suas razões para fazer estas ordenações ou classificações e vou pedir que as faça de novo considerando outros critérios ou princípios (ou aspectos). Se você tiver alguma dúvida, pode me perguntar a qualquer momento."

Finalizada a classificação, o investigador pedia ao sujeito para observar bem a formação dos grupos e verificar se estava satisfeito com a colocação das palavras em cada grupo.

"Você está contente com estes grupos e com as palavras em cada grupo? Se quiser, pode mudar estas palavras entre os grupos até estar satisfeito com o resultado."

Finalmente o investigador perguntava qual o motivo que tinha levado a criança a formar cada um dos grupos.

"Por que estas palavras estão neste grupo? O que elas têm em comum?"

$\mathrm{O}$ experimentador registrava o critério norteador da classificação, assim como os comentários apresentados pelos sujeitos e que eram relevantes para uma compreensão do significado de cada agrupamento.

\section{Classificação dirigida}

Depois da classificação livre, através do mesmo procedimento básico, o entrevistador pedia para a criança classificar as palavras-estímulo em função delas estarem associadas com a sensação de medo. A instrução para estas classificações era a seguinte:

"Agora, eu quero que você considere novamente estas mesmas palavras e, como antes, as classifique ou ordene em grupo. Mas desta vez. eu vou te dizer o critério pelo qual você vai classificar estas palavras. Em primeiro lugar, gostaria que vocêpensasse sobre estas palavras que estão escritas nestes cartões e que as ordene em grupos, em função das palavras estarem mais associadas com a sensação de medo. A questão é: quais das palavras abaixo estão, na sua opinião, mais associadas com esta sensação. Quais estão menos associadas? Quais não estão associadas? Mais especificamente, en quero que você separe estas palavras em vários grupos dependendo do fato destas estarem mais ou menos associadas com esta sensação."

Para a execução desta etapa, o experimentador colocava em ordem decrescente cinco cartões que diferiam entre si pelo tamanho. E nesta ordem, cada cartão representava um grau de associação com a palavra medo. Sendo assim, as palavras eram classificadas com base nos seguintes critérios: palavras muitíssimo associadas com o medo; palavras muito associadas com o medo; palavras mais ou menos associadas com o medo; palavras pouco associadas com o medo e palavras não associadas com o medo.

Tal procedimento era feito com intuito de auxiliar o sujeito, principalmente as crianças de orfanato, pois muitas delas não sabiam ler. Então, o examinador tinha que ler para o sujeito o conteúdo dos cartões para que este pudesse classificá-lo.

\section{Considerações sobre o Tipo de Análise}

Como nesta investigação o principal objetivo é revelar a forma como os dados se estruturam entre eles, o método de análise mais adequado depende do tipo de classificação executada. No caso de classificações livres, o mais adequado é a Análise Escalonar Multidimensional - MSA (Multidimensional Scalogram Analysis) e para as classificações dirigidas, é a Análise dos Menores Espaços - SSA (Smallest Space Analysis).

\section{Multidimensional Scalogram Analysis}

O método escalonar multidimensional (MSA Multidimensional Scalogram Analysis) foi escolhido para analisar o conteúdo da classificação livre. O seu uso foi favorecido em vista da natureza dos dados, especialmente por se saber que o MSA é conhecido por fazer uso total dos dados originais, em sua forma bruta, fazendo poucos pressupostos acerca de sua natureza e suas relações, no entanto ele é capaz de fazer com que os dados categóricos possam ser interpretados como medidas de (dis)similaridade. $\mathrm{Na}$ classificação livre, o fato de um sujeito 
formar diferentes grupos de itens não implica necessariamente uma diferença quantitativa de mais para menos dos grupos.

A matriz de dados analisada pelo MSA é retangular e mostra os itens em linhas e as categorias dos sujeitos em colunas; é também chamada de um escalograma. Essa distribuição significa que os itens são tratados como a população de pesquisa. Isso é o que Zvulun (1978) chamava de distribuição multivariada de observações, quando existe uma designação simultânea de categorias para uma dada população em um grupo de itens: "O MSA cria uma representação geométrica da distribuição multivariada (escalograma) levando em consideração as inter-relações entre os itens. Entretanto, não é feita nenhuma exigência a priori na distribuição das características dos itens ou na relação entre eles" (Zvulun, 1978, p. 240).

O programa de computador basicamente analisa a configuração de todas as categorias designadas para cada item (structuple) e as representam em um espaço geométrico; cada structuple é designada por um ponto. $\mathrm{O}$ MSA separa o espaço em regiões de tal maneira que todos os itens de um structuple (pertencente a uma categoria) localizem-se em uma mesma região. O MSA não leva em consideração as freqüências; um structuple comum a dez sujeitos é mostrado como apenas um ponto. No que diz respeito a configuração geométrica, Zvulun (1978) explica que "O MSA cria um espaço multidimensional onde 'structuples' são representadas como pontos, os itens como as partições e as categorias dos itens como as regiões das partições" (p. 240). ${ }^{6}$

De acordo com Zvulun (1978), é a melhor maneira de explorar o espaço geométrico resultante, onde os itens

\footnotetext{
${ }^{6}$ De modo a analisar o gráfico produzido pelo MSA, é necessário observar um coeficiente de contigüidade e algumas regras gerais para ajudar a definir as regiões. O coeficiente de contigüidade é um aparato que permite a análise das distorções produzidas pelos programas de computador de modo a fazer caber todos os elementos num espaço geométrico. Ele varia de +1 a -1 , respectivamente, no caso de uma contigüidade completa ou de primeira ordem ou uma discrepância total. O conceito de contigüidade envolve a relação entre os pontos em "regiões" espaciais. Um ponto interior é um que tenha como pontos mais próximos aqueles pertencentes a mesma região. Um ponto exterior é aquele que, mesmo estando numa região, tem como ponto mais próximo um pertencente a outra, o qual significa ter uma posição fronteiriça entre as regiões. Uma contigüidade de primeira ordem ocorre quando, "A distância entre um ponto interior e um ponto exterior da mesma categoria seja menor do que a distância entre aquele ponto interior e qualquer ponto que não pertença aquela categoria” (Zvulun, 1978, p.245). Uma contigüidade de segunda ordem ocorre quando para um item existem regiões de contigüidade separadas. Por exemplo, uma região localizada num canto separado por uma região de outra categoria de item e aparecendo novamente no outro canto do espaço.
}

são postos comparando as partições entre as categorias assinaladas para cada uma dos itens e então construir uma teoria que se refere às relações (neste sentido) entre os itens.

\section{Análise da Estrutura de Similaridade}

A Análise da Estrutura de Similaridade ou Análise dos Menores Espaços - (SSA - "Similarity Structure Analysis" ou "Smallest Space Analysis") foi escolhida para analisar as classificações dirigidas. De forma muito parecida ao MSA, o SSA é basicamente um escalonamento multidimensional não métrico, onde o princípio fundamental é de proximidade; quanto mais semelhantes as observações em termo de como são definidas, o mais próximo elas estarão relacionadas empiricamente, criando por assim dizer, 'regiões de contiguidade' ou 'regiões de descontinuidade' (Bailey, 1974). Em outras palavras, o SSA representa os dados no espaço, onde o grau de relacionamento entre as observações são representadas pelo inverso da distância entre os pontos - quanto mais perto os pontos, mais eles são relacionados. Desta forma, é possível se obter um mapa das variáveis em termos de espaços geométricos de dimensionalidade mínima. A distância entre os pontos reflete o grau de similaridade entre eles de acordo com uma determinada medida de similaridade, permitindo, assim, que o controle dos dados seja de um ponto de vista qualitativo ou quantitativo. Diferente do MSA, as classificações analisadas através do SSA partem do pressuposto de existir uma diferença quantitativa de mais para menos entre os diferentes grupos analisados.

A representação geométrica do SSA considera as interrelações entre os vários itens. Em nossos estudos, estes itens são palavras associadas com a emoção medo. $\mathrm{O}$ programa de computador, basicamente analisa a configuração das categorias designadas para cada item e as representa em um espaço geométrico. O SSA separa o espaço em regiões de tal maneira que, todos os itens de uma categoria se localizem em uma mesma região. A melhor maneira de explorar o espaço geométrico resultante do SSA é realizada, comparando as partições entre as categorias assinaladas para cada um dos itens, e então construir uma teoria que se refere às relações (neste sentido) entre os itens.

\section{Resultados}

\section{Classificação Livre}

Os dados da classificação livre foram analisados através do MSA, uma vez que ele compara as categorias utilizadas por cada participante para cada item, sem 
pressupor similaridade sobre o significado das categorias com o mesmo número. Em nossa investigação, os quinze itens utilizados na classificação foram selecionados a partir de uma associação livre com a emoção medo. É de se supor, portanto, que eles estejam correlacionados de certa forma com o item medo. Assim, a configuração espacial de uma classificação livre dos quinze itens, mais o item medo, implica que a configuração do MSA, pela lógica que caracteriza sua forma de análise, seja de tipo radex, tendo no centro o item medo.

A Figura 1, mostrando o resultado do MSA baseado nas classificações livres das crianças de escola particular, confirma esta hipótese. Claramente três regiões bem distintas, em volta do item medo, localizado no centro, são facilmente identificáveis. O que se torna interessante é ver quais itens compõem estas regiões e como estas estão, não só relacionadas entre si, como também se relacionam com a região central ocupada pelo item medos. Na região superior, é possível observar uma primeira região composta pelos itens Rato, Morcego, Barata, e Sanguessuga. Esta região é toda composta por animais e, desta forma, chamaremos de Animais. Do ponto de vista da localização, é mais distante do item Medo e igualmente eqüidistante das outras duas regiões.

$\mathrm{Na}$ parte inferior, lado direito da Figura 1, é possível detectar uma outra região composta pelos itens Vampiro, Papafigo, Monstro, Fantasma, Bruxa e Diabo. Esta região é toda composta por seres que podem fazer parte do imaginário e do simbólico das crianças, dependendo de suas crenças. Nesta região, o item Vampiro encontra-se um pouco afastado dos outros, na direção da parte superior da Figura 1, ocupada pela região Animais, e de fato, o vampiro pode ser também considerado um animal. O importante é que esta região encontra-se bem mais

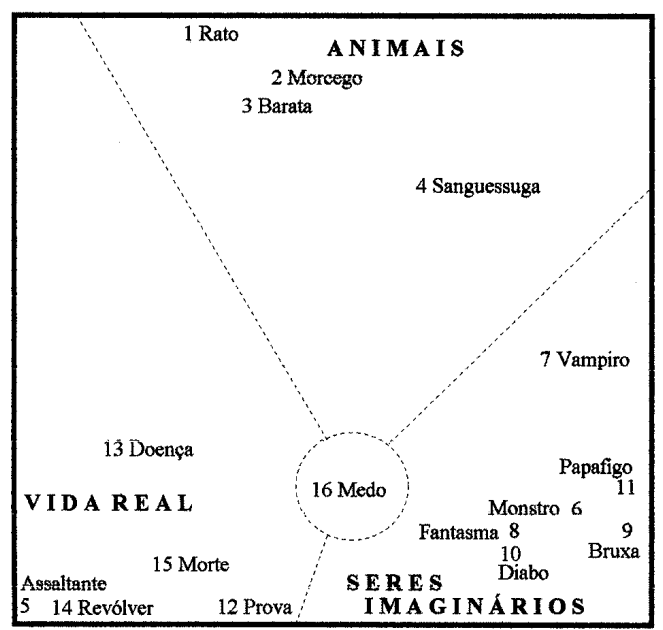

Figura 1. MSA baseado na classificação livre das crianças de escola particular. perto do item Medo do que a região Animais. Do lado oposto desta região, inferior esquerdo, é possível se observar uma outra região, composta por Doença, Prova, Morte, Assaltante e Revólver. O que caracteriza estes itens é o fato de pertencerem ao mundo da vida real e que, portanto, iremos denominar Vida Real.

Pela configuração espacial das três regiões em relação ao item Medo, a região Animais é a que se localiza mais afastada deste. Ao mesmo tempo, as regiões Seres Imaginários e Vida Real encontram-se muito mais próximas e de maneira eqüidistante associadas com a emoção do medo. Estas duas regiões são, também, igualmente distantes da região Animais.

Uma configuração similar com os mesmos grupos de itens pode ser observada na Figura 2, onde são apresentados os resultados do MSA baseado nas classificações livres das crianças de orfanato. Também para este grupo, são facilmente identificáveis três regiões bem distintas em volta do item medo, localizado no centro, mas particularmente aqui, o item morte - do grupo de itens Vida Real - encontra-se localizado no centro, próximo do item medo. A região superior é formada pelos itens que denominamos Vida Real: como Revólver, Assaltante, muito próximos entre si (parte superior direita), o item Prova (parte superior esquerda). $\mathrm{O}$ item Doença encontra-se na parte inferior esquerda, próximo da região Animais. Assim, os itens desta região estão muito dispersos se comparados aos grupos de itens das outras duas regiões, localizadas na parte inferior da projeção. Os itens da região Animais - Rato, Barata, Sanguessuga e Morcego - estão localizados na parte inferior esquerda da projeção. Estes itens encontram-se localizados muito próximos do grupo de itens Seres Imaginários. Estes últimos estão localizados no lado

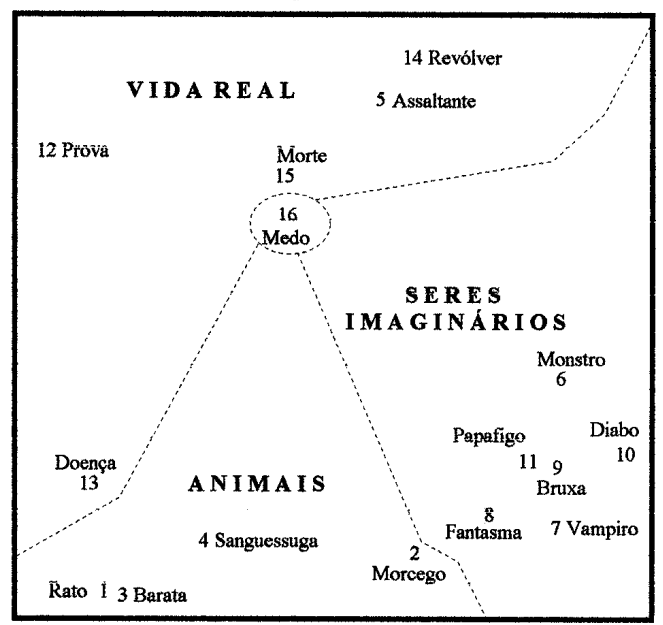

Figura 2. MSA baseado na classificação livre das crianças de orfanato. 
inferior direito da projeção. É interessante ressaltar como para as crianças de orfanato o item Doença está mais próximos dos itens Animais do que os itens Vida Real. Para as crianças de escola particular esta forte associação não é observada.

\section{Classificação Dirigida}

$\mathrm{Na}$ classificação livre, analisada através do MSA, explorou-se qual tipo de regionalização que os quinze itens iriam assumir e a relação destas regiões com o medo. $\mathrm{Na}$ classificação dirigida, o objetivo foi entender, mais em detalhes, a estrutura das relações entre estas regiões em dois grupos de crianças com experiência sóciocultural diferente - escola particular e de orfanato. O tipo de partição das regiões analisadas através do SSA permite, tanto compreender qual o tipo de ordenação entre estas regiões e qual a direção destas, como evidenciar empiricamente diferenças e similaridades comparáveis entre os dois grupos de crianças na estruturação do medo.

Na Tabela 2 estão descritas as categorizações dos quinze itens realizados pelos dois grupos de crianças (médias, desvios-padrão e análise comparativa das medias através do teste estatístico Kruskal-Wallis). Observa-se que, de um modo geral, as médias dos itens são mais elevados no grupo das crianças de escola particular, do que no grupo das de orfanato. Percebe-se também que essas médias, numa visão global, assemelham-se. No entanto, alguns itens merecem destaque, como é o caso do item 'Papafigo', cuja média encontrada no grupo orfanato $(4,00)$ é superior à encontrada na escola particular $(3,60)$. O item 'Prova' possui a única diferença, entre médias, significativa $\left(x^{2}=12,54, p<0,001\right)$, onde, neste caso, o valor encontrado para a média do grupo orfanato $(1,56)$ é inferior ao encontrado para o escola particular $(2,64)$. Outros itens que também apresentam diferenças altas entre as médias, semelhantes à encontrada com o item 'Prova', mas que, de toda maneira, não chegam a ser significantes, são os itens 'Revólver', 'Morte' e 'Morcego'.

Se forem consideradas as médias dos grupos de itens detectados nas projeções do MSA, observa-se que a média mais alta é do grupo de itens Seres Imaginários (média 3,83), seguida do grupo Vida Real (média 3,70) e enfim o grupo Animais (média 2,67).

Nas Figuras 3 e 4 são apresentados os resultados da classificação dirigida, analisada através do SSA, respectivamente, para as crianças de escola particular e de orfanato. As matrizes de correlação Kendall's Tau(b), que produziram cada uma destas figuras, encontram-se, respectivamente, nas Tabelas 3 e 4 . Em ambas as figuras, é possível observarmos a existência de três regiões, de acordo com aquelas encontradas na classificação livre realizada com as crianças de escola particular. Para ambos os grupos, as regiões encontram-se divididas de acordo com uma estrutura polar. Das três regiões, a Animais é a que apresenta características mais parecidas entre os dois grupos de crianças, apresentando os níveis de correlação mais altos entre os itens que compõem esta região para ambos os grupos (ver Tabela 2 e 3).

Todavia, as regiões Seres Imaginários e Vida Real apresentam características que diferenciam mais os dois grupos. Para as crianças de orfanato, a região Seres

Tabela 2. Médias, Desvios-Padrão e Análise Kruskal-Wallis das Categorizações dos Itens por Grupo de Crianças

\begin{tabular}{l|cccc|cc}
\hline \multirow{2}{*}{ Itens } & \multicolumn{2}{|c|}{ Particular } & \multicolumn{2}{c|}{ Orfanato } & \multicolumn{2}{c}{ Kruskal-Wallis } \\
\cline { 2 - 7 } & Média & $d p$ & Média & $d p$ & $x^{2}$ & \multicolumn{2}{c}{$p$} \\
\hline 1 Rato & 2,60 & 1,08 & 2,60 & 1,65 & 0,14 & 0,70 \\
2 Morcego & 2,36 & 1,35 & 1,93 & 1,33 & 1,99 & 0,16 \\
3 Barata & 2,68 & 1,37 & 2,37 & 1,40 & 0,85 & 0,36 \\
4 Sanguessuga & 3,52 & 1,45 & 3,37 & 1,56 & 0,14 & 0,71 \\
5 Assaltante & 4,56 & 0,58 & 4,03 & 1,37 & 0,85 & 0,35 \\
6 Monstro & 3,88 & 1,05 & 3,83 & 1,46 & 0,24 & 0,62 \\
7 Vampiro & 3,76 & 1,39 & 3,48 & 1,58 & 0,52 & 0,47 \\
8 Fantasma & 3,80 & 1,12 & 3,50 & 1,68 & 0,03 & 0,85 \\
9 Bruxa & 3,60 & 1,32 & 3,80 & 1,67 & 1,29 & 0,25 \\
10 Diabo & 4,32 & 0,99 & 4,50 & 1,14 & 1,46 & 0,22 \\
11 Papafigo & 3,60 & 1,22 & 4,00 & 1,51 & 2,86 & 0,09 \\
12 Prova & 2,64 & 1,38 & 1,56 & 1,10 & 12,54 & 0,00 \\
13 Doença & 3,64 & 1,25 & 3,90 & 1,45 & 1,44 & 0,23 \\
14 Revólver & 4,20 & 1,04 & 3,70 & 1,29 & 2,29 & 0,13 \\
15 Morte & 4,52 & 1,12 & 4,27 & 1,08 & 2,00 & 0,15 \\
\hline
\end{tabular}


Tabela 3. Matriz de Correlação de Kendall's Tau(b) entre os Itens para as Crianças de Escola Particular

\begin{tabular}{|c|c|c|c|c|c|c|c|c|c|c|c|c|c|c|c|}
\hline Itens & 1 & 2 & 3 & 4 & 5 & 6 & 7 & 8 & 9 & 10 & 11 & 12 & 13 & 14 & 15 \\
\hline 1 Rato & - & & & & & & & & & & & & & & \\
\hline 2 Morcego & 0,63 & - & & & & & & & & & & & & & \\
\hline 3 Barata & 0,46 & 0,45 & - & & & & & & & & & & & & \\
\hline 4 Sanguessuga & 0,31 & 0,17 & 0,02 & - & & & & & & & & & & & \\
\hline 5 Assaltante & 0,28 & 0,45 & 0,31 & $-0,06$ & - & & & & & & & & & & \\
\hline 6 Monstro & 0,04 & 0,27 & $-0,05$ & 0,03 & 0,26 & - & & & & & & & & & \\
\hline 7 Vampiro & 0,30 & 0,27 & 0,16 & 0,09 & $-0,03$ & 0,16 & - & & & & & & & & \\
\hline 8 Fantasma & 0,01 & 0,23 & 0,03 & $-0,09$ & 0,16 & 0,47 & 0,18 & - & & & & & & & \\
\hline 9 Bruxa & 0,20 & 0,43 & 0,26 & 0,17 & 0,09 & 0,47 & 0,42 & 0,41 & - & & & & & & \\
\hline 10 Diabo & $-0,04$ & 0,11 & $-0,16$ & $-0,03$ & 0,06 & 0,40 & 0,10 & 0,37 & 0,36 & - & & & & & \\
\hline 11 Papafigo & 0,21 & 0,33 & 0,03 & 0,28 & $-0,04$ & 0,21 & 0,35 & $-0,01$ & 0,36 & 0,03 & - & & & & \\
\hline 12 Prova & 0,32 & 0,38 & 0,09 & 0,13 & 0,25 & 0,23 & $-0,24$ & 0,06 & 0,03 & 0,01 & 0,30 & - & & & \\
\hline 13 Doença & 0,06 & 0,31 & 0,31 & 0,05 & 0,27 & $-0,02$ & $-0,17$ & $-0,01$ & 0,27 & $-0,06$ & 0,07 & 0,21 & - & & \\
\hline 14 Revólver & 0,39 & 0,38 & 0,10 & 0,04 & 0,47 & 0,20 & 0,29 & 0,38 & 0,32 & $-0,01$ & 0,13 & 0,14 & 0,05 & - & \\
\hline 15 Morte & 0,04 & 0,39 & 0,15 & 0,37 & 0,28 & 0,31 & 0,31 & 0,18 & 0,37 & 0,07 & 0,23 & 0,01 & 0,29 & 0,26 & - \\
\hline Itens & 1 & 2 & 3 & 4 & 5 & 6 & 7 & 8 & 9 & 10 & 11 & 12 & 13 & 14 & 15 \\
\hline
\end{tabular}

Tabela 4. Matriz de Correlação de Kendall's Tau(b) entre os Itens para as Crianças de Orfanato

\begin{tabular}{lccccccccccccccc}
\hline Itens & 1 & 2 & 3 & 4 & 5 & 6 & 7 & 8 & 9 & 10 & 11 & 12 & 13 & 14 & 15 \\
\hline 1 Rato & - & & & & & & & & & & & & & & \\
2 Morcego & 0,42 & - & & & & & & & & & & & & \\
3 Barata & 0,43 & 0,52 & - & & & & & & & & & & & & \\
4 Sanguessuga & 0,36 & 0,25 & 0,36 & - & & & & & & & & & & & \\
5 Assaltante & 0,17 & 0,08 & 0,13 & 0,12 & - & & & & & & & & & & \\
6 Monstro & 0,24 & 0,20 & 0,31 & 0,33 & 0,05 & - & & & & & & & & & \\
7 Vampiro & 0,25 & 0,14 & $-0,06$ & 0,18 & $-0,16$ & 0,24 & - & & & & & & & & \\
8 Fantasma & 0,11 & 0,17 & $-0,00$ & 0,25 & $-0,06$ & 0,32 & 0,54 & - & & & & & & & \\
9 Bruxa & 0,19 & 0,40 & 0,15 & 0,31 & 0,08 & 0,40 & 0,40 & 0,37 & - & & & & & & \\
10 Diabo & $-0,07$ & $-0,21$ & $-0,24$ & $-0,22$ & 0,04 & $-0,19$ & 0,40 & 0,04 & $-0,02$ & - & & & & & \\
11 Papafigo & 0,08 & 0,18 & $-0,16$ & 0,17 & 0,00 & 0,17 & 0,32 & 0,41 & 0,37 & 0,20 & - & & & & \\
12 Prova & 0,17 & 0,08 & $-0,13$ & $-0,11$ & 0,15 & $-0,32$ & 0,22 & 0,00 & $-0,21$ & 0,19 & 0,02 & - & & & \\
13 Doença & 0,20 & 0,17 & 0,16 & $-0,03$ & 0,14 & $-0,12$ & $-0,01$ & $-0,18$ & $-0,09$ & 0,03 & $-0,20$ & 0,00 & - & & \\
14 Revólver & 0,18 & $-0,10$ & $-0,03$ & 0,24 & 0,39 & 0,07 & 0,26 & $-0,07$ & 0,09 & 0,28 & 0,20 & 0,16 & 0,03 & - & - \\
15 Morte & 0,03 & 0,24 & 0,14 & 0,06 & 0,49 & 0,06 & $-0,01$ & $-0,12$ & 0,17 & 0,16 & $-0,05$ & $-0,15$ & 0,30 & 0,37 & - \\
\hline Itens & 1 & 2 & 3 & 4 & 5 & 6 & 7 & 8 & 9 & 10 & 11 & 12 & 13 & 14 & 15 \\
\hline
\end{tabular}




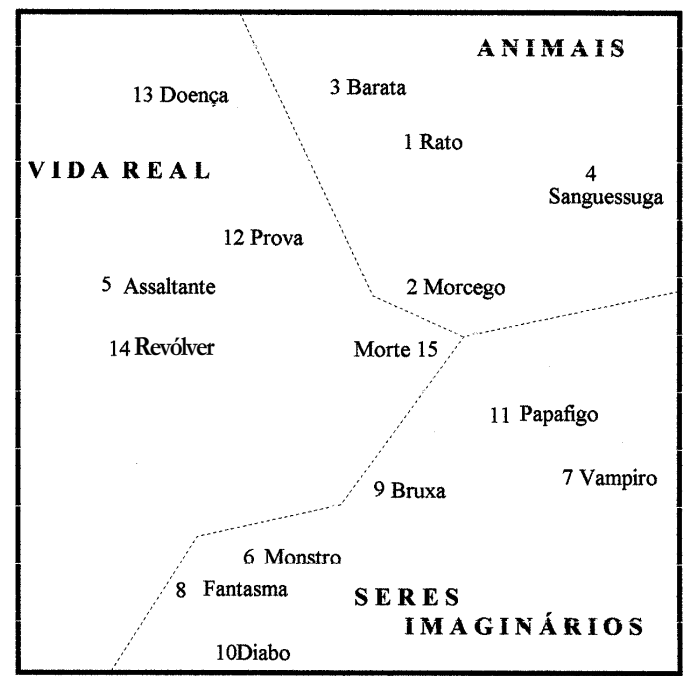

Figura 3. Projeção SSA para as crianças de escola particular

Coordenada 1 vs. coordenada 2 descrevendo a solução tridimensional Coeficiente de Alienação Guttman-Lingoes $=0,1585$

Imaginários apresenta o item Diabo bem mais afastado dos outros itens da mesma região, e muito mais próximo da região Vida Real. É possível que as crianças de orfanato considerem o Diabo como algo mais próximo da vida real do que os itens Monstro, Bruxa, Fantasma, Papafigo e Vampiro. Para as crianças de escola particular, o Diabo encontra-se muito mais próximo de Monstro e Fantasma, e mais afastado de Bruxa, Vampiro e Papafigo.

$\mathrm{Na}$ matriz de correlação, é interessante, também observar, o alto nível de correlação e proximidade espacial do item Bruxa, com os itens Monstro e Morcego (que pertence a região Animais), tanto para as crianças de escola particular como para crianças de orfanato (correlações respectivas $+0,47$ e $+0,43$ para o primeiro grupo e de $+0,40$ e $+0,40$ para o segundo grupo). Morcego, espacialmente, é o item que, em ambas as projeções, está mais próximo da região Seres Imaginários. Observa-se também o nível de correlação extremamente alto entre Vampiro e Fantasma, +0,54, para as crianças de orfanato e o nível de correlação bem mais inferior, $+0,18$, para as de escola particular. Em termo de diferença espacial e de correlação, observa-se o alto nível de correlação de tipo positiva entre Fantasma e Papafigo, $+0,41$ para as crianças de orfanato, e a negativa, de $-0,01$ entre estes dois itens, para as crianças de escola particular.

No caso da região Vida Real, as diferenças são de outra natureza e estão relacionadas com o item Morte. Para as crianças de orfanato, o item Morte encontra-se inserido dentro desta região e ao mesmo tempo, mais próximo dos itens Doença e Assaltante e mais afastado dos itens Revólver e Prova. Para as crianças de escola particular, o item Morte, apesar de poder ser considerado

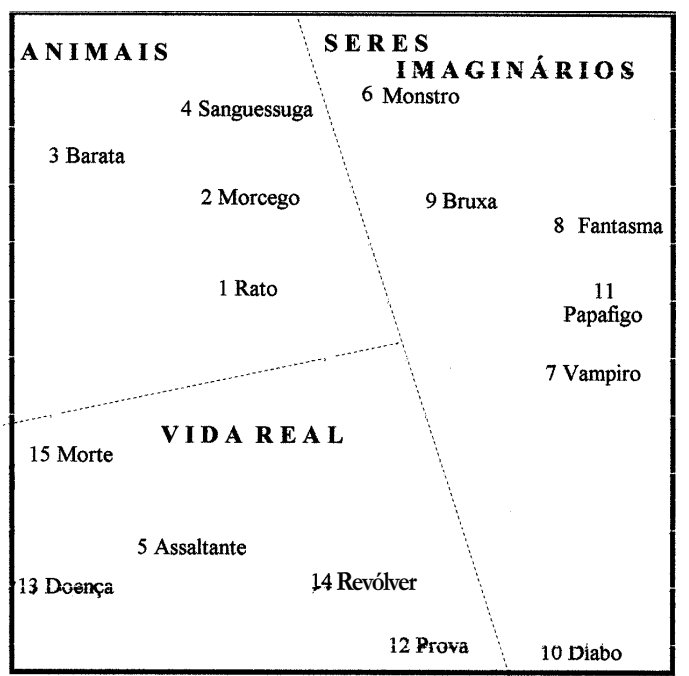

Figura 4. Projeção SSA para as crianças de orfanato

Coordenada 1 vs. coordenada 2 descrevendo a solução tridimensional Coeficiente de Alienação Guttman-Lingoes $=0,1189$

como parte da região Vida Real de acordo com uma partição do tipo polar, encontra-se localizado na área central da projeção, de maneira equidistante dos outros itens que fazem parte das três regiões. Observando a Tabela 3, na qual é apresentada a matriz de correlação dos quinze itens para as crianças de escola particular, observa-se um tipo de correlação positivo do item Morte com todos os outros itens, além desta correlação ser bastante alta, a exceção dos itens Prova e Vampiro.

Além do mais, em ambos os grupos, o item Morte apresenta sempre um nível de correlação bastante alto com os itens Assaltante e Revólver, tanto para as crianças de escola particular $(+0,28 \mathrm{com}$ Assaltante e $+0,26 \mathrm{com}$ Revólver; a correlação Revólver - Assaltante é $+0,47$ ), como para as crianças de orfanato $(+0,49$ com Assaltante e $+0,37$ com Revólver; a correlação Revólver - Assaltante é $+0,39)$. O nível de associação entre estes três itens, para ambos os grupos de crianças, reflete a maneira similar como a situação de violência vivenciada pelas pessoas nos dias de hoje, que a situação de assalto simboliza de maneira mais contundente, está fortemente associada com a idéia de morte.

Entretanto, o tipo de localização central do item Morte em relação a todos os outros itens que compõem as três regiões, aponta para a existência de uma pequena diferença na modalidade de estruturação do campo da representação do medo das crianças de escola particular em relação às crianças de orfanato. Para as primeiras, este tipo de localização do item Morte, mostra como estas sintetizam todos os outros tipos de medo e sejam, assim, mais capazes de evocar todos os outros. 


\section{Discussão}

O interesse principal desta investigação foi analisar o papel da experiência na construção da representação social do medo em crianças e, sobretudo, o nível de consenso desta representação em função desta variável, visando explorar, principalmente, novas técnicas de coleta (técnica não-verbal das classificações múltiplas) e de análise de dados (MSA e SSA). O objetivo era, assim, estabelecer, de maneira mais objetiva, o nível de consenso de diferentes grupos de crianças, comparados em relação à representação social do medo.

É importante relembrar que, do ponto de vista teórico, um problema sério que caracteriza basicamente a pesquisa sobre as representações sociais, é o fato destas utilizarem dados recolhidos a partir do indivíduo e, apesar de lidar a nível individual, inferirem conclusões gerais a nível social. Em outras palavras, o consenso ou o compartilhar, do qual uma determinada representação é objeto em um determinado grupo, é considerado como fato não questionado e não submetido a nenhum processo de verificação.

Além do mais, este problema da verificação empírica do consenso que uma representação possui em um determinado grupo, põe-se, seja no caso das pesquisas que avaliam um único grupo de sujeitos, seja no caso das que comparam as representações de dois ou mais grupos através de análises de variância (e.g., Hewstone, Jaspars \& Lallje, 1982). De fato, em ambos os casos, o consenso entre o grupo ou os grupos é, de qualquer maneira, dado como não questionável e considerado como ponto pacífico.

Considerados em seu conjunto, os resultados das projeções dos dois grupos de crianças - escola particular e orfanato - apresentaram mesmos tipos de regionalização dos itens e um mesmo tipo de partição entre as regiões. O tipo de partição é de tipo polar que, pela sua característica, não apresenta nenhuma ordem específica. As várias regiões apresentam elementos e características qualitativamente diferentes, cada uma ocupando uma direção diferente no espaço da Figura SSA, que emana de um mesmo ponto comum de origem.

A respeito das regiões encontradas, podemos dizer que estas se justificam nas falas dos sujeitos. Para a região Animais, pode-se dizer que estes itens "são animais, bichos" que "causam nojo" e "assustam", esta última justificativa vinha mais relacionada com os itens 'rato' e 'barata'. Medo de animais em crianças são algo recorrente na literatura, mostrando sua diminuição ou substituição por outros com o aumento da idade (e.g., Bleichmar, 1991; Chazan, 1989; Ferrari, 1986; Marks, 1991).
A segunda região é Vida Real, na qual se encontram fatos da vida real que levaram os participantes a dizerem que "têm medo". O "assaltante usa revólver" e pode causar uma morte, "doença" também "pode matar", e as pessoas "têm medo de morrer", e as pessoas não "querem que aconteça com elas situacõos como estas".

Para a terceira e última região, Seres Imaginários, encontra-se que seus itens "são coisas que dão medo", "dão susto", "são coisas ruins". Estas foram as justificativas mais gerais para este agrupamento. Contudo, também encontrou-se nas falas de certos sujeitos, que alguns destes itens "lembram filme de terror" e isso "dá medo". Ainda dentro deste grupo, vimos que o item 'vampiro' encontra-se próximo à região Animais. Sobre isso, pode-se afirmar que vampiro "é um animal". Stein e Jewett (1986) encontraram em crianças entre três e seis anos de idade que seres imaginários similares aos encontrados aqui, eram a principal causa de medo. Wagner (1995) também encontrou em crianças pré-escolares que o que causava mais susto eram as categorias animais e seres fictícios, $30 \%$ e $30,2 \%$, respectivamente. Este tipo de medo em nossa amostra, de aproximadamente oito anos, apresenta também a média mais alta na classificação dirigida.

Seriam interessantes a realização de estudos transversais e sobretudo longitudinais para verificar como evolui este tipo de medo em relação as outras categorias de medos. Este tipo de investigação torna-se ainda mais interessante de ser realizada, visto que Wagner (1995) em um quadro resumo da incidência dos medos em crianças de três a seis anos de idade elaborado a partir da literatura, encontrou uma incidência alta de seres imaginários somente aos quatro anos de idade. Mais especificamente, os medos de maior incidência para cada idade foram: 3 anos: animais, 4 anos: seres fictícios, animais e escuridão, 5 anos: escuridão e animais, 6 anos: escuridão, danos e fenômenos naturais. Esta preocupação é também compartilhada por Bouldin e Pratt (1998), quando observam que, apesar de padrões evolutivos no conteúdo dos medos, estes apresentam uma consistência elevada; diferenças em função do gênero e nos padrões evolutivos da prevalência dos medos não apresentam um nível de consistência satisfatório.

Voltando para uma análise das projeções, apesar de ser possível se observar configurações, cuja estrutura foram parecidas, também se observaram diferenças específicas, refletindo a experiência de cada grupo. Todavia, estas diferenças não são muito acentuadas e, obviamente, é de se esperar pelas características da experiência de vida entre os dois grupos de crianças. Podiam-se hipotetizar diferenças bem mais acentuadas. 
Desta forma, apesar das diferenças detectadas, não é possível afirmar a existência de representações sociais diferentes do medo entre estes dois grupos de crianças. Portanto, a questão do nível do consenso deste tipo de representação social - questão central no estudo das representações sociais - pôde ser avaliada empiricamente nestes dois grupos de crianças.

Naturalmente, esta constatação precisa ser considerada com cautela pela limitação que caracteriza este estudo, devido ao fato de ser uma investigação isolada no estudo da representação social do medo utilizando técnicas de coleta e de análise de dados que necessitam de ulteriores confirmações empíricas. São necessários outros estudos que utilizem amostras maiores, como também que façam uso também de outros métodos empíricos. Esta preocupação metodológica surge a partir da necessidade de poder determinar e avaliar, com maior precisão, a importância do peso do tipo de metodologia utilizada no estudo das representações sociais, especialmente quando são comparadas amostras com experiências sócio-culturais diferentes.

Entretanto, apesar das limitações, conseqüências do caráter exploratório desta investigação, é possível tecer algumas considerações de ordem mais geral sobre os tipos de medos. O dado mais interessante que surge a partir da análise destes resultados é o tipo de estrutura muito parecida que foi possível de ser encontrada entre estes dois grupos de crianças (estrutura polar), além da maior associação dos itens Vida Real e Seres Imaginários com medo, do que os itens Animais, no caso das crianças de escola particular (ver Figuras do MSA).

O que foi observado nesta investigação constitui um primeiro passo para uma análise da representação social de uma emoção. A abordagem adotada, ao mesmo tempo quantitativa e qualitativa, baseada em técnicas de categorizações não verbais, permitiu reconstruir um tipo de trama de base, apontando-se coordenadas úteis para o planejamento de futuras investigações nesta mesma área.

\section{Referências}

Amerio, P. (1986a). Individui e gruppi nell'ottica cognitiva psicosociale. Em G. Trentini (Org.), Il cerchio mágico (pp. 87-110). Milano: Angeli.

Amerio, P. (1986b). Groupes, représentations et identités sociales. Em J.L. Beauvois, R. Joule \& J.M. Monteil (Orgs.), Perspectives cognitives et conduites sociales, 1: Théories implicites et conflicts cognitifs (pp. 65-91). Cousset, Fribourg: Delval.

Amerio, P. (1987). Il problema di um soggetto conoscente ed agente nell'analisi delle condotte sociali. Rassegna Italiana di Sociologia, 28(1), 5-27.

Amerio, P, \& Di Lauro, M. (1985). Teorie cognitive delle emozioni. Giornale Italiano di Psicologia, 12(2), 167-189.
Ausebel, D. \& Sullivan, E. (1983). El desarrollo infantile, (Vol.2): El desarrollo de la personalidad. Barcelona: Paidós.

Bayley, K.D. (1974). Interpreting smallest space analysis. Sociological Methods \& Research, 3(1), 3-29.

Bleichmar, E.D. (1991). Temores y fobias: Condiciones de génesis en la infancia. Buenos Aires: Gedisa.

Bouldin, P. \& Pratt, C. (1998). Utilizing parent report to investigate young children's fears: A modification of the Fear Survey Schedule for Children-II: A research note. Journal of Child Psychology and Psychiatry, 39(2), 271-277.

Bruner, J., Goodnow, J. \& Austin, G. (1956). A study of thinking. New York: Wiley.

Buck, R. (1975). Nonverbal communication of affect in children. Journal of Personality and Social Psychology, 31, 644-653.

Buck, R. (1977). Nonverbal communication of affect in preschool children: Relationship with personality and skin conductance. Journal of Personality and Social Psychology, 35, 225-236.

Buck, R. (1978). The slide-viewing technique for measuring nonverbal sending accuracy: A guide for replication. Catalog of Selected Documents in Psychology, 8, 62, Abstract.

Buck, R. (1984). The communication of emotion. London: Guilford.

Buck, R., Savin, V.J., Miller, R.E. \& Caul, W.F. (1969). Nonverbal communication of affect in humans. Proceedings of the 77 th Annual Convention - APA, 367-368.

Campos, J. (1983). Socioemotional development. Em M. Haith \& J. Campos (Orgs.), Carmichael's manual of child psychology: Infancy and development psychobiology (Vol. 2, pp. 46-69). New York: John Wiley \& Sons.

Cannon, W.B. (1932). The wisdom of the body. New York: W.W. Norton.

Canter, D. \& Comber, M. (1985). A multivariate approach to multiple sorting. Em Sequence Analysis: Surrey Conferences on Sociological Theory and Method - II (pp. 121-143). Aldershot, Gower.

Chazan, M. (1989). Fear and anxiety in young children. Maladjustment and Therapentic Education, 7(2), 84-91.

Eckman, P. (1972). Universal and cultural differences in facial expression of emotion. Nebraska Symposium on Motivation, 1971. Lincoln: University of Nebraska Press.

Eckman, P. (1975). Unmasking the face. New Jersey: Prentice Hall.

Eckman, P. (1982). (Org.). Emotion in the human face. Cambridge: Cambridge University Press.

Ekman, P. \& Oster, H. (1979). Facial expression of emotion. Annual Review of Psychology, 30, 527-554.

Ellis, H. D. (1983). The role of the right hemisphere in face perception. Em A.W. Young (Org.), Functions of the right cerebral hemisphere (pp.23-52). New York: Academic Press.

Feldman, R.S. (1982). (Org.). Development of non-verbal behaviour in children. Berlin: Springer Verlag.

Ferrari, M. (1986). Fears and phobias in childhood: Some clinical and developmental considerations. Child Psychiatry and Human Development, 17(2), 75-87.

Fraisse, P. (1975). Les emotions. Em P. Fraisse \& J. Piaget (Orgs.), Traité de psychologie experimentale. Vol.5: Motivation, émotion et personalité (pp. 41-72). Paris: P.U.F.

Galli, I. \& Nigro, G. (1986). La rappresentazione sociale del potere in un campione di studenti universitari. Psicologia e Societá, 11(1), 20-32.

Garcia, M.J. (1992). Ambitos de interés implicados em la investigación sobre miedos infantiles. Revista de Psicologia General e Aplicada, 45, 3557.

Gazzaniga, M.S. \& Le Doux, J.E. (1978). The integrated mind. New York: Plenum Press.

Gnepp, J. (1983). Children's social sensitivity: Inferring emotions from conflicting clues. Developmental Psychology, 35, 805-814.

Gnepp, J. \& Hess, D.L.R. (1986). Children's understanding of verbal and facial display rules. Developmental Psychology, 22, 103-108.

Goodall, J. (1971). In the shadow of man. New York: Dell.

Goodall, J. (1979). Life and death at Gombe. National Geographic, 155, 592621.

Psicologia: Reflexão e Crítica, 2001, 14(1), pp. 57-72 
Gordon, H.W. (1983). Music and the right hemisphere. Em A. W. Young (Org.), Functions of the right hemisphere (pp. 121-152). New York: Academic Press.

Groat, L. (1982). Meaning in post-modern architecture: An examination using the multiple sorting task. Journal of Environmental Psychology, 2(3), $3-22$.

Guttman, L. (1968). A general nonmetric technique for finding the smallest coordinate space for a configuration of points. Psychometrika, 33, 469504.

Kruskal, J.B. (1964a). Multidimensional scaling by optimizing of fit to a nonmetric hypothesis, Psychometrika, 29, 1-27.

Kruskal, J.B. (1964b). Nonmetric multidimensional scaling: A numerical method. Psychometrika, 29, 115-129.

Harlow, H.F. (1971). Learning to love. San Francisco: Albion.

Harris, P. (1989). Children and emotion: The development of psychological understanding Oxford: Blackwell.

Hassler, M. (1990). Functional cerebral asymmetries and cognitive abilities in musicians, painters and controls. Brain and Cognition, 13, 1-17.

Heilman, K.M. \& Satz, P. (1983). Neuropsychology of buman emotions. New York: Guilford Press.

Hewston, M., Jaspars, J. \& Lallje, M. (1982). Social representations, social attributions and social identity: The intergroup images of public and comprehensive schoolboys. European Journal of Social Psychology, 12, 241-271.

Izard, C.E. (1979). Maximally discriminative facial movement scoring system. Trabalho não publicado, University of Delaware, EUA.

James, W. (1966). Psychology: The briefer course. New York: Harper Torchbooks. (Original publicado em 1890)

Kagan, J. (1975). Discrepancy, temperament and infant distress. Em M. Lewis \& L. Rosenblun (Orgs.), The origins of fear (pp. 201-224). New York: Wiley.

Kelly, G. (1955). The psychology of personal constructs. New York: Norton.

Le Bouedec, G. (1979). Contribution à la méthodologie d'étude des représentations sociales. Étude de la participation. Tese de doutorado não publicada, Universidade Católica de Louvain, Bélgica.

Lewis, Z.G. (1992). Aparência e realidade: A reconciliação de indicadores incongruentes da emoção. Psicologia: Teoria e Pesquisa, 8, 123-144.

Lewis, M \& Saarni, C. (1985). Culture and emotions. Em M. Lewis \& C. Saarni (Orgs.), The socialization of emotions (pp. 66-89). New York: Plenum Press.

Lewis, M. \& Rosenblun, L. (1975). (Orgs.), The origins of fear (pp.69-91). New York: Wiley.

Mandler, G. (1982). The construction of emotion in the child. Em C.E. Izard (Org.), Measuring emotions in infants and children (Vol. 1, pp.164-187) Cambridge: Cambridge University Press.

Marks, I. (1991). Miedos, fobias e rituales. Barcelona: Martinez Roca.

Mason, W.A. (1961). The effects of social restriction on the behaviour of rhesus monkeys: III. Tests of gregariousness. Journal of Comparative and Physiological Psychology, 54, 287-290.

Michalson, L. \& Lewis, M. (1985). What do children know about emotions and when do they know it? Em M. Lewis \& C. Saarni (Orgs.), The socialization of emotions (pp. 97-121). New York: Plenum Press.

Miller, G.A. (1956). The magical number seven, plus or minus two. Psychological Review, 43, 81-97.

Miller, R. E., Banks, J. \& Kuwahara, H. (1966). The communication of affect in monkeys: Cooperative reward conditioning. Journal of Genetic Psycbology, 108, 121-134.

Miller, R.E., Banks, J. \& Ogawa, N. (1962). Communication of affect in "cooperative conditioning" of rhesus monkeys. Journal of Abnormal and Social Psychology, 64, 343-348.

Miller, R.E., Banks, J. \& Ogawa, N. (1963). Role of facial expression in "cooperative-avoidance conditioning" in monkeys. Journal of Abnormal and Social Psychology, 67, 24-30.

Monteiro, C.M.G. \& Roazzi, A. (1987). Representações sociais e o processo de classificações múltiplas. Algumas implicações metodológicas no estudo da estruturação socio-espacial da cidade. Psicologia Argumento, $7(6), 55-78$.
Moscovici, S. (1984). The phenomenon of social representation. Em R. Farr \& S. Moscovici (Orgs.), Social Representation (pp.34-56). Cambridge: Cambridge University Press.

Mowrer, O. H. (1960). Learning theory and behaviour. New York: John Wiley $\&$ Sons.

Nigro, G. \& Galli, I. (1988). La rappresentazione sociale della paura in soggetti in etá evolutiva: Primi rilievi. Psicologia e Societá, 13(1), 57-68.

Oliverio Ferraris, A. (1977). Il bambino in casa e a scuola. Bologna: Zanichelli.

Oliverio Ferraris, A. (1980). Psicologia della paura. Torino: Boringhieri.

Oliverio Ferraris, A., \& Pilleri Senatore, R. (1986). Evoluzione delle paure in rapporto all'etá. Giornale Italiano di Psicologia Clinica, 1(1), 39-44.

Orthony, A. Clore, G.L. \& Collins, A. (1988). The cognitive structure of emotions. New York: Cambridge University Press.

Piaget, J. (1981). Intelligence and affectivity: Their relationship during child development. Palo Alto, California: Annual Reviews.

Plutchick, K. (1980). A general psychoevolutionary theory of emotion. Em R. Plutchik \& H. Kellerman (Orgs.), Emotion Theory, Research, and Experience (pp.46-75). New York: Academic Press.

Reissland, N. (1985). The development of concepts of simultaneity in children's understanding of emotions. Journal of Child Psychology and Psycbiatry, 26, 811-824.

Reissland, N. (1988). The development of emotion in young children. Tese de Doutorado não-publicado, Department of Experimental Psychology, University of Oxford. Oxford, Inglaterra.

Roazzi, A. (1995). Categorização, formação de conceitos e processos de construção de mundo: Procedimento de classificações múltiplas para o estudo de sistemas conceituais e sua forma de análise através de métodos de análise multidimensionais. Cadernos de Psicologia, 1, 127.

Roazzi, A. (1999a). Pesquisa básica com psicologia cognitiva e sua relação com a psicologia social. Arquivos Brasileiros de Psicologia, 51(1), 23-54.

Roazzi, A. (1999b). Lar-doce-lar: Rainha ou rei? A representação da participação masculina nas tarefas domésticas e a lógica de sua distribuição em casais de nível sócio-doméstico baixo. Arquivos Brasileiros de Psicologia, 51(4), 7,39.

Roazzi, A. Federicci, F. C. B. \& Carvalho, M. R. (1999, junho). A facet approach to the study of fear adults. Trabalho apresentado na VII International Facet Theory Conference, Berne, Suíça.

Roazzi, A. \& Monteiro, C.M.G. (1991, Junho). Social representation of the professional urban mobility and its implication for school failure. Anais do XIV International School Colloquium, Braga, Portugal.

Roazzi, A. \& Monteiro, C.M.G. (1995). A representação social da mobilidade profissional em função de diferentes contextos urbanos e suas implicações para a evasão escolar. Arquivos Brasileiros de Psicologia, 47(3), 39-73.

Ross, E.D. (1981). The aprosodias. Functional-anatomic organization of the affective components of language in the right hemisphere. Archives of Neurology, 38(9), 561-569.

Russell, J.A. (1989). Culture, scripts and children's understanding of emotions. Em C. Saarni \& P.L. Harris (Orgs.), Children's understanding of emotion (pp.121-129). New York: Cambridge University Press.

Saarni, C. (1989). Children's understanding of strategic control of emotional expression in social transactions. Em C. Saarni \& P.L. Harris (Orgs.), Children's understanding of emotion (pp. 210-234). New York: Cambridge University Press.

Schachter, S. (1967). The interaction of cognitive and physiological determinants of emotional state. Em J.F. Perez, R.C. Sprinthall, G.S. Grosser \& P.J. Anastasion (Orgs.), General psychology: Selected readings (pp. 25-47). Princeton: D. Van Nostrand.

Shepard, R.N. (1962). The analysis of proximities: Multidimensional scaling with an unknown distance function. Psychometrika, 27, 125-139 (Parte 1), 219-246 (Parte 2).

Scherer, R. \& Ekman, P. (1984). Approaches to emotions. Hillside, N.J.: Erlbaum. Schiffman, S.S., Reynolds, M.L. \& Young, F.W. (1981). Introduction to multidimensional scaling. Theory, methods and applications. New York: Academic Press. 
Schwartz, R.M. \& Trabasso, T. (1984). Children's understanding of emotions. Em C.E. Izard, J. Kagan \& R.B. Zajonc (Orgs.), Emotion, cognition and behaviour (pp. 86-108). Cambridge: Cambridge University Press.

Sherif, M. \& Sherif, C. (1969). Social Psychology. New York/Tokio: Harper \& Row.

Shye, S. (1978). Theory construction and data analysis in the behavioural sciences. São Francisco: Jossey-Bass.

Souza, J . de, (1988). Métodos Estatísticos nas Ciências Psicossociais. Vol. V Métodos de escalagem psicossocial: Uni e Multidimensinal. Brasilia: Thesaurus.

Sroufe, L.A. (1979). Socioemotional Development. Em J. Osofsky (Org.), Handbook of infant development. New York: John Wiley \& Sons.

Stein, N. L. \& Levine, L.J. (1989). The causal organization of emotional knowledge: A developmental study. Cognition and Emotion, 3(4), 343378.

Stein, N.L. \& Jewett, J.L. (1986). A conceptual analysis of anger, fear and sadness. Em C.E. Izard \& P.B. Read (Orgs.), Measuring emotion in infants and children (pp. 122-151). Cambridge: Cambridge University Press.

Szalay, L.B. \& Deese, J. (1978). Subjective meaning in culture: An assessment through word association. Hillsdale, NJ: Erlbaum.

Tajfel, H.C. (1981). Human groups and social categories. Cambridge: Cambridge University Press.

Torgerson, W.S. (1952). Multidimensional scaling: Theory and method. Psychometrika, 17, 401-419.
Torgerson, W.S. (1958). Theory and methods of scaling. New York: Wiley.

Trentin, R. (1988). Emozioni e processi cognitivi. Em V. D’Urso \& R. Trentin (Orgs.), Psicologia delle emozioni (pp. 54-75). Bologna: Il Mulino. Vygotsky, L. (1934). Thought and language. Boston: MIT.

Ward, L. M. \& Russel, J.A. (1981). Cognitive set and the perception of place. Environment and Behaviour, 13(5), 610-632.

Wagner, A. (1995). Os fatores psicossociais do medo infantil: Sua ocorrência e características na idade pré-escolar. Psico, 26(1) 89-106.

Wilson, M.A. \& Canter, D.V. (1990). The development of central concepts during professional education: An example of a multivariate model of the concept of architectural style. Applied Psychology: An International Review, 39(4), 431-455.

Wimmer, H. \& Perner, J. (1983). Beliefs about beliefs: Representations and constraining function of wrong beliefs in young children's understanding of deception. Cognition, 13, 103-128.

Zlotowicz, M. (1974). Les peurs enfantines. Paris: PUF.

Zvulun, E. (1978). Multidimensional Scalogram Analysis: The method and its applications. Em S. Shye (Org.), Theory construction and data analysis in the behavioural sciences (pp. 96-125). London: Jossey-Bass.

Recebido em 5/07/1999

Revisado em $7 / 12 / 2000$

Aceito em 9/01/2001

Sobre os autores:

Antonio Roazzi é professor da Universidade Federal de Pernambuco.

Fabiana C. B. Federicci é psicóloga e estudante da Universidade Federal de Pernambuco.

Margaret Wilson é professora da University of Camterbury, Inglaterra. 